\title{
The relationship between EFL learners' personality types and their cognitive learning styles
}

Tahriri, Abdorreza $\measuredangle$

Department of English Language and Literature, University of Guilan, Rasht, Iran (atahriri@gmail.com)

Divsar, Hoda

Department of English Language, Payame Noor University (PNU), Tehran, Iran (hodadivsar@gmail.com)

Ashouri, Fatemeh

Department of English Language, Payame Noor University (PNU), Tehran, Iran (fatemeashouri@yahoo.com)

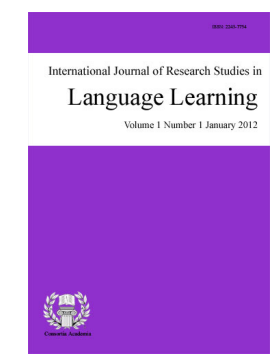

ISSN: $2243-7754$ Online ISSN: 2243-7762

OPEN ACCESS

$\begin{array}{lll}\text { Received: } 4 \text { July } 2014 & \text { Revised: } 19 \text { August } 2014 \quad \text { Accepted: } 20 \text { August } 2014\end{array}$

Available Online: 24 August 2014 DOI: $10.5861 /$ ijrsll.2014.843

\section{Abstract}

The aim of the present study was to investigate the relationship between male and female EFL learners' learning styles and their personality types. To this end, one-hundred English majors took part in the study. The participants consisted of 78 females and 22 males. The Group Embedded Figures Test (GEFT) was used to assess the participants' field dependent/independent (FD/FI) learning styles. The Personality Style Inventory (PSI) was also administered to assess the personality types of the participants. The data obtained from the PSI showed that the most frequent personality types were ISTJ (introvert, sensing, thinking, judging), ESTJ (extrovert, sensing, thinking, judging), and ESTP (extrovert, sensing, thinking, perceiving) personality types, and the least frequent types were ENFJ (extrovert, intuitive, feeling, judging), and INFJ (introvert, intuitive, feeling, judging). Moreover, the results of the GEFT showed that $52 \%$ of the subjects were of FI learning style type and $48 \%$ of them had a FD learning style. The results of Chi-Square test and Fisher's Exact Test also showed that there was no statistically significant relationship between males and females' learning styles and personality types. The EFL instructors' awareness of these differences in personality types and learning styles can enable them to create a more dynamic atmosphere in the classroom through designing activities that meet the learning preferences of different types of learners.

Keywords: learning style; personality type; survey; EFL 


\section{The relationship between EFL learners' personality types and their cognitive learning styles}

\section{Introduction}

Learning style is defined as "the particular way in which a learner tries to learn something" (Richards \& Schmidt, 2002, p. 85). Different learners use various ways to solve their learning problems. Some may need more explanations; some may want to write down the material in order to learn them, while others may not do so. These different ways of coping with learning problems are called learning styles. Learning styles are categorized from three perspectives: analytic versus global which shows whether the learners focus on details or focus on the main topic; visual versus auditory versus tactile which relates to learners' sensory preferences; and intuitive versus concrete that refers to concentration in an abstract way or a concentration on concrete information (Richards \& Schmidt, 2002). In addition, Keefe (1979; cited in Brown, 2000) defined learning styles as cognitive, affective, and physiological characteristics that show how learners understand the learning environment and how they respond to it. Cornett (1983) also defined learning styles as "the overall patterns that give general direction to learning behavior" (cited in Oxford; 2003, p. 359). Rollins (1990) also stated that learning styles show individual differences in the way they gather information, process them, and assimilate the information. He stated that individuals tend to place themselves in situations where they can use their preferred learning style.

Moreover, Richards and Schmidt (2002) defined personality type as "those aspects of an individual's behavior, attitudes, beliefs, thoughts, actions, and feelings which are seen as typical and distinctive of that person and recognized as such by that person and others" (p. 395). There are several models of personality types; however, the most famous theory of personality types is Jung's Theory of Psychological Types. The basic premise of Jung's theory is that each person understands his/her surrounding world in a specific way and drives his/her energy from different sources and this difference makes him/her a unique person. In this theory of personality types, the focus is on the ways of gathering information and processing them. Myers and Briggs designed their personality type indicator in 1942. This type indicator is a self-report questionnaire that helps people understands their potential qualities. It includes four bipolar dimensions that categorize people as extrovert/introvert, thinking/feeling, sensing, intuitive, and judging/perceiving (Chih-Kang \& Hong-Shan, 2010).

As such, it is reasonable to posit that losing sight of learners' varied learning styles and personality types does not let EFL instructors tailor their instruction to meet learners' diverse needs and preferences. The purpose of this study is to investigate this relationship between personality type and learning style of male and female EFL learners.

\section{Literature Review}

Human learning is influenced by a plethora of factors. As Burton and Nelson (2005) mentioned, nowadays students are more diverse regarding their educational, social, and cultural background than before. All these factors influence students' learning styles in one way or another. Duff, Boyle, and Dunleavy (2004) also stated that individual differences including personality type have a great impact on students' learning. Fallen (2006; cited in Threeton \& Walter, 2009) indicated that ignoring a student's personality type can lead to a conflict in the educational process, since an individual's personality type and learning style are related to each other.

In order to assess learning style of pre-service agricultural teachers, Cano, Garton, and Raven (1992) used Witkin's Group Embedded Figures Test. They investigated the learning styles of 25 pre-service agriculture teachers, 7 female and 18 male learners, at Ohio State University during spring and fall of 1990. In this study, those students who scored above group mean were considered as FI (field-independent) and those who scored below the group mean were considered as FD (field-dependent). They found that about $44 \%$ of the learners were 
The relationship between EFL learners' personality types and their cognitive learning styles

FD and about $56 \%$ of them were FI. In addition, it was found that about $29 \%$ of female learners were FD and $71 \%$ of them were FI, while $50 \%$ of male learners were FD and $50 \%$ of them were FI. In another related study, Witkin (1977; cited in Lucas-Stannard, 2003) administered the Group Embedded Figures Test to a group of learners. The participants were required to find a simple figure in a more complex figure and based on the amount of the time spent to find the simple figure they were classified as FD /FI. According to this study, those participants who spent more time to find the figures were considered as FD and those who found the figures quickly were considered as FI. Based on the results of this test, Witkin found that most people were classified as being completely FD or completely FI. Moreover, Marrison and Frick (1994) investigated the learning styles of 53 agricultural economics from Agriculture school during spring of 1992. They used the GEFT to find the students' learning style. The analysis of the information showed that $43.4 \%$ of students were FD learners, while $56.6 \%$ of them were FI learners.

In another study, Estadt (1997) investigated the personality types of 135 agricultural students at the Ohio State University during 1990 to 1994 . He used the MBTI test to assess the participants' personality types. Based on the data obtained from the participants, it was found that $20.7 \%$ of subjects were of ESTJ (extrovert, sensing, thinking, judging) personality type, $17 \%$ of them were of ISTJ (introvert, sensing, thinking, judging) type, and $12.6 \%$ of them were of ESFJ types which were the three most frequent personality types among the participants. In addition, ISTJ, ISTP, ESTP (extrovert, sensing, thinking, perceiving), ESTJ types comprised $49.6 \%$ of the population and $21.5 \%$ of the population included ISFJ, ISFP, ESFP, and ESFJ personality types. About $19 \%$ of the population was of INFJ (introvert, intuitive, feeling, judging), INFP, ENFP, and ENFJ (extrovert, intuitive, feeling, judging) personality types and about $17 \%$ of them were of INTJ, INTP, ENTP, and ENTJ personality types. $20.7 \%$ of male participants had ESTJ personality type and 19.5 of them were of ISTJ personality type. Among female participants, $22.9 \%$ of them were of ESTJ type and $18.8 \%$ of them had ESFJ personality type.

In addition, Ishaya, Henderson, and McCrackson (1992) found that the personality type of Extension educators were similar to personality types of adult educators. Using Myers-Briggs Type Indicator (MBTI), they investigated personality types of 116 of Ohio State University Extension educators and found that 57\% of Extension educators were extroverts. $57 \%$ of these people had preferences toward sensing, 58\% thinking, and $65 \%$ judging. Moreover, they found that in contrast to adult educators, Extension educators showed $66.3 \%$ preferences for judging and this is more than their tendency to be perceiving (33.7\%). In addition, Extension educators showed a tendency to be more extrovert-judging than introvert-perceiving.

In another study, Le Sage, Venneman, Patton, and Hallock (2008) studied the students' preferred personality type measured by Keirsey Temperament Sorter (KTS) of 63 undergraduate business students who took part in a web-based course. They used the KTS test including 70 items with two choices for each one that investigates the students' personality profile and describes their temperament and personality features. It uses Jung's psychological Type Inventory and identifies eight opposing personality types that are extrovert, introvert, feeling, thinking, intuitive, sensing, perceiving, and judging. They analyzed the data based on MBTI and found that $18 \%$ of the participants were of NF type, $11 \%$ of SP type, and 5\% of NT type. In addition, they found that $56 \%$ of male and $66 \%$ of female learners were of SJ type, while $24 \%$ of female and $20 \%$ of male learners were of SP personality type. $12 \%$ of male participants were of NT and NF personality types, while $3 \%$ of female learners were of NF type and $8 \%$ of them were of NT personality type.

As far as the relationship between personality type and learning style is concerned, several major studies have been conducted that are reviewed here:

Carey et al. (1989; cited in Davis, 2004) found that there was a correlation between perception (sensing/intuitive) and orientation (judging/perceiving) measured by MBTI and learning styles measured by Group Embedded Figures Test (GEFT). They found that individuals with intuitive and perception types were generally less FD than individuals with sensing and judging preferences.

In a study, Harasym, Leong, Lucier, and Lorscheider (1996; cited in Larrabee, 2005) investigated the 
relationship between personality types and learning styles. They used MBTI and Gregorc's Style Delineator in their study. They found that subjects with thinking-feeling personality types had abstract sequential and abstract random learning styles. Those who had sensing-intuitive preferences had concrete sequential and concrete random learning styles.

In another study, Meisgeier and Swank (1998; cited in Larrabee, 2005) studied the personality type and learning style of 429 high school student. In this study, they used three tests: the Murphy-Meisgeier Type Indicator (MMTIC), the Dunn Learning Style Indicator (LSI), and the Renzulli Learning Style Indicator (LSI). The results of this study showed that the extroversion/introversion and judging/perceiving personality types were related to specific learning styles. The researchers concluded that personality type is a useful tool to understand students' learning preferences.

In order to investigate the relationship between learning styles and personality types of participants, Davis (2004) conducted a descriptive correlational study to describe the relationship between personality type and learning styles of Extension Community Development program professionals in Ohio. In addition, he studied those who were employed in this program in terms of their primary work assignment, length of tenure, academic major, educational attainment, age, and gender during April to May 2004; he found that about $67 \%$ of Extension Community Development program professionals had FD learning style. He found that about $24 \%$ of these people had ISTJ personality type and $12 \%$ were of INTJ type. $53.7 \%$ of these individuals were of introvert type and $37.3 \%$ of them were of extrovert type. In addition, $60 \%$ of professionals preferred sensing function over intuition and more than $60 \%$ of them preferred thinking functions over feeling, and $74.6 \%$ indicated a preference for judging over perceiving. Davis concluded that there was a negligible correlation between learning style and personality type and the strongest association was between sensing-intuition personality type and learning style.

In a study on the relationship between learning styles and academic performance of Students at University of Port Elizabeth in 2003, Vawda (2005) investigated learning styles of 395 first-year university students and used Kolb's learning style model to find the learners' learning styles. It was found that accommodators and divergers were the dominant learning styles among six faculties. Most of the learners tended to use active experimentation in order to process information and showed an extroverted personality type.

In another study, Zimmerman et al. (2006) compared personality types and learning styles of Engineering, Agricultural, Systems Management (ASM) students, and faculty in an Agricultural and Biological Engineering (ABE) department during spring of 2005. They used the MBTI and GEFT instruments to assess the participants' personality types and learning styles respectively. They found that most of the ASM students showed stronger preference for extrovert and sensing personality types than ABE students, since most of them were of ESTP type. In addition, it was found that between these two groups, female participants preferred feeling type more than male participants. Analysis of the results of the GEFT test also showed that among all groups of students, most of the participants preferred FI learning style. Based on these results, they concluded that it is important to equip these students with applied laboratory settings, practical problem situations, and to allow them to be free to choose their projects.

In another study, Threeton and Walter (2009) studied the relationship between learning styles and personality types of 189 postsecondary automotive technology students during the spring of 2008 at three public postsecondary institutions in Pennsylvania. They used the Holland's Self-Directed Search (SDS) test that is a self-administered assessment test, and Kolb's Learning Style Inventory (LSI) to investigate the participants' personality types and learning styles respectively. They found that $84.1 \%$ of the participants had Realistic personality type. Then the LSI was administered to assess the participants' learning style. $39.8 \%$ of the participants were found to have the accommodating learning style that was the most frequent learning style among other learning style types and the least frequent learning style was Assimilators (16.5\%). Based on the results of the LSI, they concluded that post-secondary automotive students had a diverse distribution of learning styles. A significant relationship was found between Realistic personality type and the Accommodating learning 
style of $37.8 \%$ of the participants.

\section{Research Questions}

In this study, the relationship between EFL learners' personality type (based on Myers-Briggs Personality Type Indicator) and cognitive learning style, i.e., field-dependent (FD) vs. field independent (FI) (based on Witkin's Learning Style Model) was investigated. The purpose of this study was to determine the relationship between learning style and personality type in order to shed light on the role of these two important learner variables. In addition, gender differences in learning style and personality type and their relationship with each other was taken into consideration in order to find better way of dealing with gender-related problems in language classes. As such, the following questions were addressed in the present study:

1. What are the pre-intermediate male and female EFL learners' personality types?

2. Is there any significant difference between male and female EFL learners concerning their personality types?

3. What are the pre-intermediate male and female EFL learners' cognitive learning styles?

4. Is there any significant difference between male and female EFL learners concerning their cognitive learning styles?

5. Is there any significant relationship between pre-intermediate EFL learners' personality type and their cognitive learning style?

\section{Method}

\subsection{Participants}

This study was conducted with randomly-selected English majors from Rasht Azad University and Payame Noor University of Rasht both of which are located in Guilan Province, Iran. As such, the whole participants were selected from one single province to neutralize the effect of cultural background of the participants that might potentially affect the outcome of the study. One-hundred thirty English majors took part in the first phase of the study. The purpose of the study was to investigate learning styles and personality types of pre-intermediate level English majors. About 30 of the participating EFL learners were not at the pre-intermediate level. As a result, they were excluded from the study and the total number of participants was 100 EFL learners. The intention was to select the participants who were all BA English majors at pre-intermediate level to control for the effect of diversity of language learners.

\subsection{Instruments}

Three instruments were used in the present study: Oxford Placement Test (OPT), Group Embedded Figures test (GEFT), and Personal Style Inventory (PSI). The first test was used to measure the participants' language proficiency; the second instrument was used to assess their learning style, and the third one was used to determine the personality type of the participants of the present study.

Oxford Placement Test - This test includes 50 multiple-choice items consisting of grammar and vocabulary questions. In addition, it includes a reading text with 10 comprehension question. The last part of this test contains an optional writing activity. The present study was concerned with the pre-intermediate level as a control variable. Based on the scoring procedure of the test, the students who have 21 to 31 correct answers in the grammar and vocabulary parts, five to seven correct answers in the reading section, and gain eight scores from the writing section are considered to be at the pre-intermediate level of language proficiency. 
Group Embedded Figures Test (GEFT) - The purpose of this 25-item test is to assess people's learning style and categorize them as field dependent (FD) or field independent (FI). Field dependence/independence is identified by peoples' orientation toward their surrounding environment and their ability in identifying a part of a whole when it is separated from its main context. The GEFT includes three sections. The first section contains seven items that are prepared as practice tests in order to familiarize the subjects with the test structure. Each of the second and third sections contains nine items that are the main test items of this test. In order to complete this test, the participants should identify some simple figures that are hidden in a more complex figure in about 15 minutes. Those who answer 12 or more than 12 items correctly are categorized as FI learners and those who answer 11 or less than 11 items correctly are categorized as FD learners.

Personality Type Indicator (PSI) - Personality Type Indicator (PSI) was designed by Hogan and Champagne based on the Myers-Briggs Personality Type Indicator in 1979. The purpose of this 32-item test is to assess individuals' personality type regarding Jung's Theory of Psychological Types and like MBTI categorizes personality type as four dimensions. What each dimension includes is like a continuum that has two opposite ends. This test assesses the personality types based on the individuals' preferences in the ways of gathering and processing information and categorizes them as being extrovert/introvert, intuitive/sensing, thinking/feeling, and judging/perceiving. The items are arranged in pairs and each item includes two sentences. Each sentence in each item shows one dimension of a continuum.

\subsection{Reliability and Validity Issues}

Regarding Group Embedded Figures Test, Witkin (1971; cited in Davis, 2004) administered the GEFT to male and female participants and used a Spearman-Brown analysis test, and reported a reliability coefficient of .89. In addition, he reported an instrument validity of 0.82 for male and 0.79 for female participants. In addition, Oltman et al. (1971) used a test-retest method to determine the reliability of the GEFT and reported a reliability coefficient of .82 for both male and female participants (cited in Soozandehfar \& Souzandehfar, 2011). Bosacki, Innerd, and Towson (1997; cited in Soozandehfar \& Souzandehfar, 2011) also reported a validity score of 0.82 for male and .63 for female participants.

For the present study, test-retest method was used in order to calculate the reliability of the GEFT. The reliability coefficient of the GEFT was found to be .89 which shows it is highly reliable. In order to determine the reliability of PSI, Hogan and Champagne (1980; cited in Davis, 2004) used a Pearson product moment test and compared the subjects' estimated scores with their real PSI scores. They reported reliability coefficients of 0.60 for extrovert/introvert scale, 0.74 for sensing/intuitive scale, 0.66 for thinking/feeling scale, and 0.61 for judging/perceiving scale. In addition, they used Phi correlations to determine instrument validity and reported correlations of $0.78,0.55,0.90$, and 0.71 for each dimension. In order to calculate the reliability of the PSI for the present study, Chronbach's alpha was calculated for each scale separately. The reliability coefficient for introversion/extroversion scale was 0.68 , for intuitive/sensing scale was 0.60 , for thinking/feeling scale was 0.55 , and for perceiving/judging scale was 0.55 . This shows that PSI is a reliable instrument to assess personality type.

\subsection{Data collection and analysis procedures}

In the first stage of data collection, the GEFT and PSI tests were translated into Persian in order to ensure the participants' understanding. To ensure the validity of the translation, they were back-translated into English by two experienced EFL instructors. At first, a pilot study was conducted with twenty-four English majors during their class time in the fall of 2011. In this stage, the OPT, GEFT, and PSI were all administered to the participants in order to ensure their reliability and validity. The purpose of the pilot study was to make sure the instruments were appropriate for the intended participants. In the next stage, the major phase of the study was carried out. To this end, the instruments were administered to English majors during their class time in the winter of 2012. The objectives and procedure of the test were explained to the participants first. Then they completed the tests during a 90-minute period. 
The relationship between EFL learners' personality types and their cognitive learning styles

To analyze the data, descriptive statistics, Chi-square and Fisher's Exact Test were utilized. In order to answer the first research question, the PSI was administered to the participants and by calculating the scores that they gave to each item, their personality types were determined. Then, a Pearson Chi-Square was run to determine the relationship between personality type and gender. In order to answer the third research question, the GEFT was administered to the participants and by calculating the number of their correct answers, their learning styles were determined. Regarding the fourth research question, a Chi-Square and a Fisher's Exact test were utilized to determine the relationship between the participants' learning styles and their gender. Finally, a Chi-Square test was run to answer the fifth research question and determine the relationship between the male and female learners' learning styles and their personality types.

\section{Findings and Discussion}

\subsection{Personality types of males/females}

The PSI was used in the present study to investigate the personality types of male and female EFL learners. As it is shown in table 1, the most frequent personality types were ISTJ (Introvert, Sensing, Thinking, Judging), ESTJ (Extrovert, Sensing, Thinking, Judging), and ESTP (Extrovert, Sensing, Thinking, Perceiving) personality types with respective frequencies of $24(24 \%), 23(23 \%)$, and $10(10 \%)$. In addition, the least frequent personality types were ENFJ (Extrovert, Intuitive, Feeling, Judging), INFJ (Introvert, Intuitive, Feeling, Judging) with respective frequencies of $1(1 \%)$. It should be mentioned that INFP personality type was not preferred by any of the participants and, as such, it is not given in table 1.

Moreover, it was found that the most frequent personality types among female participants were ISTJ and ESTJ personality types. $23.1 \%$ of the female participants were of ISTJ type and $23.1 \%$ of them were of ESTJ type. In addition, the least frequent personality types among female subjects were ENTP (Extrovert, Intuitive, Thinking, Perceiving), ENFJ (Extrovert, Intuitive, Feeling, Judging), ENTJ (Extrovert, Intuitive, Thinking, Judging), INFJ (Introvert, Intuitive, Feeling, Judging), and INTJ (Introvert, Intuitive, Thinking, Judging) personality types with frequencies of $1(1.3 \%)$ for each one. Table 1 summarizes the statistics that were obtained from PSI (Personal Style Inventory) test and shows the personality types of male and female participants of the study.

Table 1

Descriptive Statistics (PSI)

\begin{tabular}{|c|c|c|c|c|c|c|}
\hline \multirow{2}{*}{ Personality Type } & \multicolumn{2}{|c|}{ Male } & \multicolumn{2}{|c|}{ Female } & \multirow{2}{*}{\multicolumn{2}{|c|}{ Total }} \\
\hline & No. & Percentage & No. & Percentage & & \\
\hline ISTJ & 6 & $6.0 \%$ & 18 & $18.0 \%$ & 24 & $24 \%$ \\
\hline ENFP & 0 & $.0 \%$ & 3 & $3.0 \%$ & 3 & $3 \%$ \\
\hline ENTP & 1 & $1.0 \%$ & 1 & $1.0 \%$ & 2 & $2 \%$ \\
\hline ESTJ & 5 & $5.0 \%$ & 18 & $18.0 \%$ & 23 & $23 \%$ \\
\hline ESFJ & 0 & $.0 \%$ & 5 & $5.0 \%$ & 5 & $5 \%$ \\
\hline ENFJ & 0 & $.0 \%$ & 1 & $1.0 \%$ & 1 & $1 \%$ \\
\hline ENTJ & 1 & $1.0 \%$ & 1 & $1.0 \%$ & 2 & $2 \%$ \\
\hline ESFP & 0 & $.0 \%$ & 3 & $3.0 \%$ & 3 & $3 \%$ \\
\hline ISFJ & 0 & $.0 \%$ & 4 & $4.0 \%$ & 4 & $4 \%$ \\
\hline INFJ & 0 & $.0 \%$ & 1 & $1.0 \%$ & 1 & $1 \%$ \\
\hline INTJ & 1 & $1.0 \%$ & 1 & $1.0 \%$ & 2 & $2 \%$ \\
\hline ISTP & 2 & $2.0 \%$ & 8 & $8.0 \%$ & 10 & $10 \%$ \\
\hline ISFP & 2 & $2.0 \%$ & 3 & $3.0 \%$ & 5 & $5 \%$ \\
\hline INTP & 2 & $2.0 \%$ & 3 & $3.0 \%$ & 5 & $5 \%$ \\
\hline ESTP & 2 & $2.0 \%$ & 8 & $8.0 \%$ & 10 & $10 \%$ \\
\hline Total & 22 & $22 \%$ & 78 & $78 \%$ & 100 & $100 \%$ \\
\hline
\end{tabular}

As table 1 reveals, the frequency of different personality types shows that the most frequent personality type 
Tahriri, A., Divsar, H., \& Ashouri, F.

among male participants is ISTJ type. It was found that about $27.3 \%$ of the male participants preferred ISTJ personality types. In addition, the least frequent personality types among male participants were ENFP (Extrovert, Intuitive, Feeling, Perceiving), ESFJ (Extrovert, Sensing, Feeling, Judging), ENFJ (Extrovert, Intuitive, Feeling, Judging), ESFP (Extrovert, Sensing, Feeling, Perceiving), ISFJ (Introvert, Sensing, Feeling, Judging), and INFJ (Introvert, Intuitive, Feeling, Judging). None of the male participants preferred these personality types.

Moreover, the results of the PSI showed that $51 \%$ of the participants had introvert personality types, while $49 \%$ of them had extrovert personality types. Furthermore, the results showed that among introverts $38(48.7 \%)$ of them were female and $13(59.1 \%)$ of them were male. Regarding extroversion, forty female participants and nine male participants had extrovert personality types.

In addition, $67 \%$ of the participants had ST (Sensing, Thinking) personality types including $52(66.6 \%)$ female and $15(68.1 \%$ ) male subjects, while $17 \%$ of the subjects had SF (Sensing, Feeling) personality types that comprised $15(19.2 \%)$ female and $2(9.1 \%)$ male participants. In addition, the results of the PSI showed that $11 \%$ of the subjects had NT (Intuitive, Thinking) personality types, while 5\% of them had NF (Intuitive, Feeling) personality type. It should be mentioned that all of the participants with NF personality types were female.

Regarding the last scale of personality types (judging/perceiving), the results showed that $62 \%$ of the subjects had judging personality types and 38\% of them had perceiving personality type. In addition, $49(62.8 \%)$ of the female and $13(59.1 \%)$ of the male participants were of $\mathrm{J}$ type, while $29(37.1 \%)$ of the female and 9 $(40.9 \%)$ of the male participants were of perceiving type.

\subsection{Difference between males/females personality types}

As it was shown in the preceding section, the results of the PSI revealed that the number of introvert and extrovert participants was not much different but as the statistics showed, the number of female participants was higher than their male counterparts regarding both introvert and extrovert personality types. Moreover, the data showed that the number of Sensing-Thinking participants was more than Sensing-Feeling subjects. As it was shown, the number of ST and SF female participants was more than their male counterparts. In addition, the number of Intuitive-Thinking participants was more than Intuitive-Feeling subjects with more female participants with NT and NF personality types. In addition, it should be mentioned that regarding Sensing/Intuitive and Thinking/Feeling personality type scale, the data showed that the number of Sensing and Thinking subjects was more than the number of Intuitive and Feeling subjects. Therefore, as the data presented in table 2 shows, the results of the Chi-Square test showed that with $95 \%$ confidence (alpha= 0.05 ), it can be concluded that there is no statistically significant difference between males' and females' personality types. The results of the Chi-square test is summarized in table 2:

Table 2

Chi-Square (The Difference between Personality Types of Male and Female Participants)

\begin{tabular}{lccc}
\hline & Value & Df & Asymp. sig. (2-sided) \\
\hline Pearson Chi-Square & 9.598 & 14 & .791 \\
Likelihood ratio & 12.510 & 14 & .565 \\
N of valid cases & 100 & & \\
\hline
\end{tabular}

The findings of this study regarding the relationship between personality types of male and female participants are congruent with those of Cano, Garton, and Raven (1992) Estadt (1997) and Davis (2004).

\subsection{Learning styles of males/females}

In order to assess the participants' learning styles, the GEFT was used in the present study. Table 3 presents the data elicited from the participants about their preferred learning styles. The results of the GEFT showed that 
The relationship between EFL learners' personality types and their cognitive learning styles

$48(48 \%)$ of the participants had field dependent (FD) learning style, while 52 (52\%) of them had a field independent (FI) learning style. Then the data was analyzed for each gender separately and it was found that 12 $(54.5 \%)$ of the male participants preferred an FD learning style. However, the results of the GEFT showed that $32(46.2 \%)$ of female participants preferred an FD learning style. Moreover, the data obtained from the participants showed that $52(52 \%)$ of them preferred an FI learning style. Regarding FI learning style, the results of the GEFT showed that $10(45.5 \%)$ of the male participants preferred an FI learning style, while regarding female participants, this amount was about four times more than males. The results showed that $42(53.8 \%)$ of female participants preferred an FI learning style. The descriptive statistics related to the results of the GEFT are given in table 3 :

Table 3

Descriptive statistics (GEFT)

\begin{tabular}{lcccccc}
\hline & \multicolumn{3}{c}{ Male } & \multicolumn{2}{c}{ Female } & \multicolumn{2}{c}{ Total } \\
\cline { 2 - 6 } & No. & Percentage & No. & Percentage & \\
\hline & & & & & & \\
Field Dependent & 12 & $12 \%$ & 36 & $36 \%$ & 48 & $48 \%$ \\
Field Independent & 10 & $10 \%$ & 42 & $42 \%$ & 52 & $52 \%$ \\
\hline Total & 22 & $22 \%$ & 78 & $78 \%$ & 100 & $100 \%$ \\
\hline
\end{tabular}

\subsection{Differences between males/females'learning styles}

The data obtained from the GEFT showed that females were more field independent than males and females were more field dependent than males too (see table 3). Moreover, the data showed that the number of female FI participants was more than female FD participants. In addition, the number of male FD participants was more than the number of male FI participants. The results of Pearson Chi-Square test and Fisher's Exact test are presented in table 4 based on which with $95 \%$ confidence (alpha=0.05), it can be concluded that there is no statistically significant difference between males' and females' learning styles.

Table 4

Chi-Square \& Fisher's Exact Test (Relationship between Learning Styles of Male and Female Participants)

\begin{tabular}{llllll}
\hline & Value & Df & $\begin{array}{l}\text { Asymp.Sig } \\
(2 \text {-sided })\end{array}$ & $\begin{array}{l}\text { Exact Sig } \\
(2 \text {-sided })\end{array}$ & $\begin{array}{l}\text { Exact Sig } \\
(1 \text {-sided })\end{array}$ \\
\hline Pearson Chi-Square & .484 & 1 & .487 & & \\
Continuity Correction & .206 & 1 & .650 & & .325 \\
Likelihood Ratio & .484 & 1 & .487 & .630 & \\
Fisher's Exact Test & 100 & & & & \\
N of Valid Cases & 100 & & & & \\
\hline
\end{tabular}

Based on the results of the Chi-square and Fisher's Exact tests, the findings of the present study are in line with the results of Cano, Garton, and Raven (1992), Marrison and Frick (1994), Estadt (1997) and Davis (2004).

\subsection{Relationship between learning styles and personality types}

As explained in the preceding sections, the results of the PSI showed that the most frequent personality types among male and female participants were ISTJ, ESTJ, and ESTP personality types. In addition, the data obtained from the GEFT showed that the most frequent learning styles among male and female participants were FD learning style FI learning style respectively. The results of personality type, learning style and gender cross-tabulation showed that $11 \%$ of the ISTJ type participants preferred FD learning style and $13 \%$ of them preferred FI learning style, while $12 \%$ of those learners who preferred ESTJ personality type preferred an FD learning style and $11 \%$ of them preferred an FI learning style. Furthermore, $4 \%$ of those who preferred ESTP personality type preferred an FD learning style and $6 \%$ of them preferred an FI learning style. 
Tahriri, A., Divsar, H., \& Ashouri, F.

Moreover, it was found that the number of ISTJ personality type female participants who preferred an FD or FI learning styles was the same. The results of the cross-tabulation showed that $9(11.5 \%)$ of them preferred an FD learning style and $9(11.5 \%)$ of them preferred an FI learning style. Regarding male participants with ISTJ personality type, the results of cross-tabulation showed that $2(9.1 \%)$ of them preferred an FD learning style, while $4(18.2 \%)$ of them preferred an FI learning style.

Regarding the second most frequent personality type in the present study, ESTJ, the results of cross-tabulation revealed that $12 \%$ of subjects with ESTJ personality type preferred an FD learning style and $11 \%$ of them preferred an FI learning style. Among female participants with ESTJ personality type, the results of cross-tabulation showed that the number of FD and FI participants is the same. It was found that $9(11.5 \%)$ of them preferred an FD learning style and 9 (11.5\%) of them preferred an FI learning style, while among male participants with ESTJ personality type, it was found that 3 (13.6\%) of them preferred an FD learning style and 2 $(9.1 \%)$ of them preferred an FI learning style.

As it was mentioned, the third frequent personality type in the present study was ESTP personality type. It was found that $4 \%$ of subjects with ESTP personality type preferred an FD learning style and $6 \%$ of them preferred an FI learning style. Among female subjects with ESTP personality type, 3 (3.8\%) of them preferred an FD learning style and $5(6.4 \%)$ of them preferred an FI learning style. Among male subjects with ESTP personality type, it was found that the number of FD and FI subjects was the same. The results showed that 1 $(4.5 \%)$ of them preferred an FD learning style and 1 (4.5\%) of them preferred an FI learning style.

The results of Pearson Chi-Square test showed that with 95\% confidence (alpha $=0.05$ ), we can conclude that there is no statistically significant relationship between males' and females' learning styles and personality types (see table 5). This finding is in line with that of Estadt (1997) and Davis (2004).

\section{Table 5}

Chi-Square (Relationship between Learning Styles \& Personality Types of Males and Females)

\begin{tabular}{lllll}
\hline Gender & & Value & df & Asymp. Sig (2-sided) \\
\hline \multirow{2}{*}{ Female } & Pearson Chi-Square & 8.723 & 14 & \\
& Likelihood Ratio & 10.767 & 14 & .704 \\
\multirow{5}{*}{ Male } & N of Valid Cases & 78 & & \\
& Pearson Chi-square & 7.749 & 8 & .458 \\
& Likelihood Ratio & 10.403 & 8 & .238 \\
\multirow{2}{*}{ Total } & N of valid cases & 22 & & .835 \\
& Pearson Chi-square & 8.931 & 14 & .713 \\
& Likelihood Ratio & 10.654 & 14 & \\
\hline
\end{tabular}

\section{Conclusions and Implications}

According to the data obtained from the Personal Style Inventory (PSI), the most frequent personality types among male and female EFL learners were ISTJ, ESTJ, and ESTP personality types and the least frequent personality types were ENFJ, INFJ, and INFP. Moreover, it was found that the most frequent personality types among female participants were ISTJ, and ESTJ, and the most frequent personality type among male participants was ISTJ. According to the data elicited through the PSI, it was found that there was no significant difference between EFL learners' personality types across gender. In addition, the results of the PSI showed that the participants had a tendency toward both extroversion and introversion personality types and that Sensing and Thinking personality types were more dominant among the participants.

The data obtained from the GEFT showed that the most frequent learning style among male and female EFL learners was Field Independent (FI) learning style. Furthermore, the data showed that the most frequent learning style among male and female participants were FD learning style and FI learning style respectively. 
The relationship between EFL learners' personality types and their cognitive learning styles

Based on the results of the GEFT, it was found that there was no significant difference between male and female EFL learners. Furthermore, the results of the GEFT test for this group of participants showed that FI learning style is more preferred than FD learning style.

According to the results of the PSI and the GEFT and Pearson Chi-Square analysis, it was found that there was no significant relationship between intermediate male and female EFL learners' cognitive learning styles and their personality type. Moreover, the results of learning style and personality type cross-tabulation showed that the most frequent personality types among the participants were ISTJ and ESTJ.

The findings of the study revealed that EFL learners have a variety of learning styles and personality types. Teachers' awareness of these differences can help them match their teaching styles with their students' personality types and choose more appropriate activities that can enhance EFL learners' learning achievement. In addition, it is to be noted that this study was concerned with a group of Asian EFL learners. It is necessary to note that context can be particularly important as EFL learners might have various types of personality type and learning styles in different contexts. In fact, localizing instruction can be a worthwhile endeavor through which the role of context can be highlighted.

The data obtained through the PSI showed that the most frequent personality types among participants were ISTJ and ESTJ and the number of participants with these personality types was almost equal. In addition, it was found that the number of introvert and extrovert participants was almost the same. As a result, taking account of these differences in personality types can be important for teachers in planning class activities and it can be highly important in course planning and preparing instructional materials.

Moreover, the data elicited through the GEFT showed that the number of participants with FD or FI learning style was almost equal. It is important to pay due attention to these differences in learning styles. It should be noted that preparing activities and instructional materials that match the needs of both field dependent and field independent EFL learners can be helpful for them in learning process and can increase their achievement. As Shirani Bidabadi and Yamat (2012) also pointed out, all EFL instructors should be aware of their students' learning style preferences in order to match their teaching styles with their students' learning style preferences.

Some suggestions for further research on EFL learners can be put forward. In order to find more about the effect of individual differences on learners' learning styles or personality types, the relationship between affective factors that influence learning process and learning style or personality type and their effect on language achievement can be studied. In addition, the relationship between students' demographic characteristics and their learning style and personality type is another issue that can be important in the realm of language studies. Furthermore, the relationship between sociocultural factors and learning styles or personality types can be an interesting issue for the teachers and course designers. In addition, it can be helpful to investigate the relationship between students' learning styles or personality types and their proficiency in different language skills.

\section{References}

Brown, H. D. (2000). Principles of language learning and teaching. (4 ${ }^{\text {th }}$ ed.). New York: Pearson Education.

Burton, L. J., \& Nelson, L. J. (2005). The relationship between personality, approaches to learning, and academic success in first-year psychology distance education students. Retrieved October 6, 2011, from http://eprints.usq.edu.au/3210/

Cano, J., Garton, B. L., \& Raven, M. R. (1992). Learning styles, teaching styles, and personality styles of pre-service teachers of agricultural education. Journal of Agricultural Education, 33(2), 46-52. http://dx.doi.org/10.5032/jae.1992.01046

Chih-Kang, W., \& Hong-Shan, L. (2010). Learning style and personality type of hospitality undergraduate students of Taiwan and the United States. Retrieved January 5, 2012, from http://www.ge.cyut.edu.tw/cyutge/file/201007271008530.09\%20Learning\%20Style\%20and\%20Person 
Tahriri, A., Divsar, H., \& Ashouri, F.

ality\%20Type\%20Profiles\%20of.pdf

Davis, G. A. (2004). The relationship between learning style and personality type of extension community development program professionals at the Ohio State University. Retrieved September 28, 2011, from http://etd.ohiolink.edu/send-pdf.cgi/Davis\%20Gregory\%20A.pdf?osu1092425344\&dl=y

Duff, A., Boyle, E., \& Dunleavy, J. (2004). The relationship between personality, approach to learning, and academic performance. Personality and Individual Difference, 36, 1907-1920. http://dx.doi.org/10.1016/j.paid.2003.08.020

Estadt, M. J. (1997). The relationship between learning styles and personality types of students enrolled in an agricultural teaching methods class. Retrieved January 15, 2012, from http://etd.ohiolink.edu/send-pdf.cgi/EstadtMichael John.pdf

Ishaya, J. B., Henderson, J. L., \& McCrackson, J. D. (1992). Relationship between assessment center performance and psychological types of cooperative extension agents in Ohio. Journal of Agricultural Education, 33(4), 53-61. http://dx.doi.org/10.5032/jae.1992.02053

Larrabee, F. (2005). A comprehensive study of the relationship between personality type and learning styles of students as they apply to the classroom teacher. Retrieved September 28, 2011, from http://www2.uwstout.edu/content/lib/thesis/2005/2005larrabeef.pdf

Le Sage, T. A., Venneman, S. S., Patton, B. A., \& Hallock, D. E. (2008). Business undergraduate temperaments, student electronic activity, and selected demographic characteristics on course achievement in an on-line university learning environment. European Journal of Social Sciences, 5(4), 8-20.

Lucas-Stannard, P. (2003). Cognitive styles: A review of the major theories and their application to information seeking virtual environments. Retrieved January 10, 2012, from http://www.personal.kent.edu/ plucasst/Cognitive\%20Styles.pdf

Marrison, D. L., \& Frick, M. J. (1994). The effect of agricultural students' learning styles on academic achievement and their perceptions of two methods of instruction. Journal of Agricultural Education, 35(1), 26-30. http://dx.doi.org/10.5032/jae.1994.01026

Oxford, R. L. (2003). Language learning styles and strategies: An overview. Retrieved February 1, 2012, from http://web.ntpu.edu.tw/ language/workshop/read2.pdf

Richards, J. C., \& Schmidt, R. (2002). Longman dictionary of language teaching and applied linguistics ( $3^{\text {rd }}$ ed.). London: Pearson Education.

Rollins, T. J. (1990). Analysis of theoretical relationships between learning styles of students and their preferences for learning activities. Journal of Agricultural Education, 31(1), 64-70. http://dx.doi.org/10.5032/jae.1990.01064

Shirani Bidabadi, F., \& Yamat, H. (2012). The relationship between English listening proficiency levels and learning styles. GEMA Online Journal of Language Studies, 12(4), 1041-1055.

Soozandehfar, M. A., \& Soozandehfar, M. (2011). The effects of field-dependent/field-independent cognitive styles and gender on second language speaking performance. California Linguistic Notes, 36(2), 1-21.

Threeton, M. D., \& Walter, R. A. (2009). The relationship between personality type and learning style: A study of automotive technology students. Journal of Industrial Teacher Education, 46(2), 48-74.

Zimmerman, A. P., Johnson, R. G., Hoover, T. S., Hilton, J. W., Heinemann, P. H., \& Buckmaster, D. R. (2006). Comparison of personality and learning styles of engineering students, Agricultural Systems Management students, and faculty in an Agricultural and Biological Engineering department. Education Division of ASABE, 49(1), 311-317. http://dx.doi.org/10.13031/2013.20213 